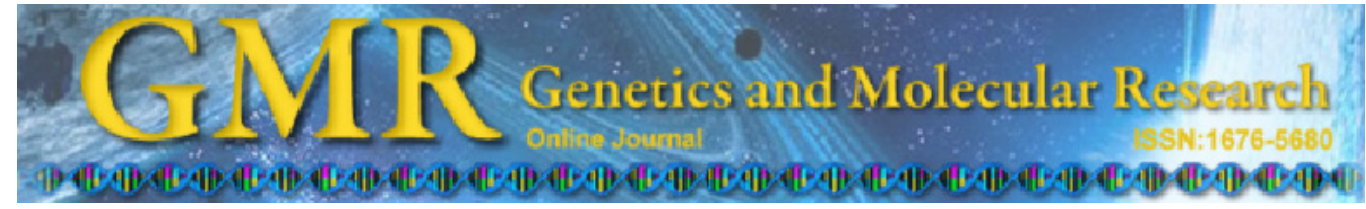

\title{
Association between retinoid-X receptor-gamma genetic polymorphisms and diabetic retinopathy
}

\author{
C.-H. Hsieh ${ }^{1}$, D. Pei ${ }^{2}$, Y.-J. Hung ${ }^{1}$ and F.-C. Hsiao ${ }^{1}$ \\ ${ }^{1}$ Department of Internal Medicine, Division of Endocrinology and Metabolism, \\ National Defense Medical Center, Tri-Service General Hospital, Taipei, Taiwan \\ ${ }^{2}$ Department of Internal Medicine, Medical School, Catholic Fu Jen University, \\ Cardinal Tien Hospital, Taipei, Taiwan \\ Corresponding author: C.-H. Hsieh \\ E-mail: changhsun@seed.net.tw
}

Genet. Mol. Res. 10 (4): 3545-3551 (2011)

Received March 10, 2011

Accepted August 25, 2011

Published December 5, 2011

DOI http://dx.doi.org/10.4238/2011.December.5.4

\begin{abstract}
Retinoid-X receptor (RXR) is one of the members of the nuclear hormone receptor superfamily. It forms heterodimers with many nuclear receptors, such as the peroxisome proliferative-activated receptor, which has been proposed to be involved in diabetic complications, including retinopathy. A recent study revealed that RXR-alpha has antioxidant properties and is associated with diabetic retinopathy. We found that the RXR-gamma gene is involved in the pathogenesis of diabetic nephropathy. We also hypothesized that the RXR-gamma gene has a role in the development of diabetic retinopathy. We examined 213 diabetic patients, who were divided into retinopathy or no retinopathy groups. Nine selected single nucleotide polymorphisms (SNPs) in the RXR-gamma gene were evaluated. The diabetic retinopathy group had longer diabetes duration, higher body mass indexes, and higher systolic blood pressure, as well as higher concentrations of fasting plasma glucose, blood urine nitrogen, and creatine. One SNP - rs3818569 of the RXR-gamma gene was found to be associated with increased risk for diabetic retinopathy in both allele and genotype frequencies $(\mathrm{P}=0.0023$ and 0.0057 , respectively). Analysis with multivariate logistic regression
\end{abstract}


revealed that the dominant RXR-gamma GG genotype is a risk factors for the development of diabetic retinopathy (odds ratio $=2.388 ; 95 \%$ confidence interval $=1.17-4.875)$. We conclude that the RXR-gamma rs3818569 SNP is associated with diabetic retinopathy development in the Taiwanese population.

Key words: Diabetic retinopathy; Single nucleotide polymorphism; Type 2 diabetes

\section{INTRODUCTION}

Diabetic retinopathy (DR) is the leading cause of new cases of blindness among adults worldwide. Retinopathy develops in approximately $21 \%$ of patients newly diagnosed with type 2 diabetes and in approximately $60 \%$ of patients with type 2 diabetes within the first 2 decades after diagnosis (Fong et al., 2003). Diabetic retinopathy begins with mild nonproliferative abnormalities, followed by moderate and severe nonproliferative DR, and finally progresses to proliferative DR. Several factors influence the prevalence and development of retinopathy in patients with type 2 diabetes. These factors include the duration of diabetes (Klein et al., 1984a), glycemic control (Anonymous, 1998a), and blood pressure control (Anonymous, 1998b). The first 2 factors are the most important (Cahill et al., 1976). However, it has been reported that some patients with type 2 diabetes develop retinopathy even if they have adequate glycemic control, and other patients develop DR even if their glycemic control is poor (Anonymous, 1998b; Klein et al., 1984b). Therefore, other factors such as genetics may have important roles in the development of DR.

The Diabetes Control and Complications Trial showed that retinopathy tends to cluster in families. This was shown by the observation that the incidence of retinopathy was increased if siblings had severe DR (Anonymous, 1997). However, there was no strong observation in type 2 diabetes with similarly familial aggregation. Twin studies suggested that genetic factors may be important in the etiology of retinopathy (Lesile and Pyke, 1982). Subsequently, evidence of genetic involvement in susceptibility to DR was proposed (Parving et al., 1996). The association between several candidate genes, which included endothelial nitric oxide synthase gene (Chen et al., 2007), vascular endothelial growth factor gene (Awata et al., 2002; Ray et al., 2004; Suganthalakshmi et al., 2006; Buraczynska et al., 2007) and angiotensin 1-converting enzyme gene (Fujisawa et al., 1998) and DR has been evaluated, but inconclusive data have been reported from these trials.

The retinoid-X receptor (RXR) is one of the members of the nuclear hormone receptor superfamily. It forms heterodimers with many nuclear receptors, such as the peroxisome proliferative-activated receptor (PPAR), and mediates the biological effects of several hormones and drugs (Kastner et al., 1995; Mangelsdorf and Evans, 1995). PPAR alpha and PPAR gamma are involved in the regulation of lipid and glucose metabolism, and have an important impact on the development of diabetic microvascular complications, which include nephropathy and retinopathy. Furthermore, a recent study revealed that RXR alpha (RXRA) poses antioxidants properties and is associated with the development of DR (Chai et al., 2008; Roy et al., 2009). Besides, we found that the RXRG gene has a role in the pathogenesis of diabetic nephropathy, as noted in our previous article (Hsieh et al., 2006). Therefore, we hypothesized that the RXRG gene may also have a role in the development of DR. 


\section{MATERIAL AND METHODS}

\section{Study population}

The study is an extension of our previous study that evaluated the genetic association of diabetic nephropathy. The results of this previous study have been published (Hsieh et al., 2006). In brief, case-control groups of 264 patients with type 2 diabetes, all patients of Han Chinese decent, were recruited from the Tri-Service General Hospital in Taipei, Taiwan. The control group comprised 120 patients with type 2 diabetes without nephropathy, and the case group comprised 144 diabetic patients with nephropathy. All the recruited patients were between 30 and 75 years of age and had been diagnosed with diabetes more than 5 years before enrolment. The average duration of disease of both groups has exceeded 10 years in our study.

\section{Definition of DR and study groups}

Most of the subjects (213 subjects) had been enrolled in a previous study and were referred to the ophthalmology department. These patients underwent fundus photography, and the findings were assessed by ophthalmologists. Patients with no signs of DR or with fewer than 5 dots or blot hemorrhages were assigned to the diabetes without retinopathy (NDR) group. The remaining patients were assigned to the DR group on the basis of the presence of microaneurysms, hemorrhage, cotton wool spots, intraretinal microvascular abnormalities, hard exudate, venous beading, and new vessel formation. According to these criteria, we assigned 132 patients to the DR group and 81 patients to the NDR group. Approval was obtained from the Internal Review Board of the Tri-Service General Hospital before the study was performed, and each patient signed an Informed Consent form.

\section{Laboratory evaluation}

A blood sample was drawn after a 10-12 h overnight fast. The plasma was separated from the blood within $1 \mathrm{~h}$ and stored at $-30^{\circ} \mathrm{C}$ until analysis. The samples obtained from 0 minutes were analyzed for fasting plasma glucose and lipid levels. Plasma glucose levels were determined by a glucose oxidase method using an analyzer (YSI 203 glucose analyzer, Scientific Division, Yellow Spring Instrument Company, Inc., Yellow Spring, OH, USA). Both the triglyceride and total cholesterol levels were measured by the dry, multilayer analytical slide method using the Fuji Dri-Chem 3000 analyzer (Fuji Photo Film Corporation, Minato-Ku, Tokyo, Japan). Serum high-density lipoprotein cholesterol level was determined by an enzymatic cholesterol assay method after dextran sulfate precipitation.

\section{DNA extraction, genotyping and gene selection}

DNA was isolated from the blood samples by using a QIAamp DNA Blood kit according to manufacturer instructions (Qiagen). The quality of the isolated genomic DNA was assessed for each sample by agarose gel electrophoresis analysis. The quantity of DNA in each sample was determined by spectrophotometry. The SNPs were genotyped by the TaqMan method on an Applied Biosystems (ABI) Prism 7900 instrument. SNP IDs were referred to the dbSNP database of the National Center for Biotechnology Information. These SNPs were 
confirmed not to reside in a repetitive area of the genome, which reduces erroneous associations. Nine SNPs in the RXRG gene were analyzed.

\section{Statistical analysis}

In this case-control study, the mean values of the demographic parameters are presented as mean \pm standard deviation (SD) and compared by the Student $t$-test. The allele and genotype frequencies of the 176 SNP loci were compared between patients in the DR group (case) and the NDR group (control) by using the $\chi^{2}$ statistics for contingency tables. The comparison of allele frequencies had one degree of freedom in a two-by-two contingency table. The genotype comparison uses a three-by-two contingency table, comparing three diplotypes with respect to two traits (i.e., DR and NDR). In addition, the genotype comparison was evaluated between dominant allele carriers and non-carriers by using contingency tables. Moreover, a multivariate logistic regression test was performed with DR as dependent factor and other covariate factors as co-variables to identify the independent factors in the development of DR. A $p$ value of less than 0.05 was considered significant.

\section{RESULTS}

\section{Study group comparison}

The demographic characteristics of the subjects are summarized in Table 1. The durations of diabetes were greater in the DR group than in the NDR group. In addition, subjects in the DR group had a higher body mass index and systolic blood pressure; higher levels of plasma fasting glucose, BUN and Cr. Diabetic retinopathy and diabetic nephropathy are both complications of diabetes, therefore a higher percentage of diabetic nephropathy patients were observed in the DR group. The correlation between the retinopathy and nephropathy status is 0.37 , showing a positive medium correlation.

\section{Table 1. Demographic and clinical parameters of the study subjects.}

\begin{tabular}{|c|c|c|c|}
\hline & $\mathrm{DR}(\mathrm{N}=81)$ & $\operatorname{NDR}(\mathrm{N}=132)$ & $P$ value \\
\hline Age (years) & $59.4 \pm 8.7$ & $60.4 \pm 8.0$ & 0.447 \\
\hline Duration of diabetes (years) & $17.3 \pm 8.0$ & $12.5 \pm 6.1$ & $<0.001$ \\
\hline Gender $(\%$ male $)$ & $35 / 81(43.2 \%)$ & $66 / 132(50.0 \%)$ & 0.285 \\
\hline BMI $\left(\mathrm{kg} / \mathrm{m}^{2}\right)$ & $26.1 \pm 4.6$ & $24.7 \pm 3.6$ & 0.014 \\
\hline Weight (kg) & $66.1 \pm 12.8$ & $64.5 \pm 12.3$ & 0.386 \\
\hline Waist circumference $(\mathrm{cm})$ & $88.2 \pm 10.6$ & $88.1 \pm 10.3$ & 0.949 \\
\hline $\mathrm{FPG}(\mathrm{mg} / \mathrm{dL})$ & $184.5 \pm 64.9$ & $166.4 \pm 50.6$ & 0.026 \\
\hline $\mathrm{HbAlc} \mathrm{( \% )}$ & $8.94 \pm 1.90$ & $8.59 \pm 1.47$ & 0.169 \\
\hline Total cholesterol (mg/dL) & $208.9 \pm 49.0$ & $200.4 \pm 41.2$ & 0.178 \\
\hline LDL-C $(\mathrm{mg} / \mathrm{dL})$ & $116.2 \pm 36.6$ & $111.0 \pm 29.0$ & 0.256 \\
\hline Triglyceride (mg/dL) & $193.0 \pm 132.1$ & $190.4 \pm 175.0$ & 0.908 \\
\hline HDL-C $(\mathrm{mg} / \mathrm{dL})$ & $40.5 \pm 11.3$ & $42.4 \pm 12.4$ & 0.258 \\
\hline$\%$ of diabetic nephropathy & $61 / 81(70.1 \%)$ & $49 / 132(35.6 \%)$ & $<0.001$ \\
\hline BUN (mg/dL) & $25.8 \pm 12.8$ & $20.2 \pm 12.3$ & 0.002 \\
\hline Creatinine $(\mathrm{mg} / \mathrm{dL})$ & $1.60 \pm 0.95$ & $1.26 \pm 0.67$ & 0.004 \\
\hline \multicolumn{4}{|l|}{ Blood pressure $(\mathrm{mmHg})$} \\
\hline Mean systolic pressure (mmHg) & $136.4 \pm 18.9$ & $128.6 \pm 16.9$ & 0.02 \\
\hline Mean diastolic pressure $(\mathrm{mmHg})$ & $77.6 \pm 12.8$ & $74.7 \pm 9.6$ & 0.06 \\
\hline
\end{tabular}

Data are reported as means \pm standard deviation. $\mathrm{BMI}=$ body mass index; HbA1c $=$ glycated hemoglobin $\mathrm{A} 1 \mathrm{C} ; \mathrm{LDL}-\mathrm{C}=1$ low-density lipoprotein-cholesterol; HDL-C = high-density lipoprotein-cholesterol; FPG = fasting plasma glucose; $\mathrm{BUN}=$ blood urea nitrogen . 


\section{SNP association analysis}

Only one SNP, rs3818569, of nine RXRG genes was significantly different both in allele and genotyping frequencies (P value: 0.0023 and 0.0057 respectively, Table 2 ). In addition, multivariate logistic regression analysis revealed that diabetic duration, FPG and dominant RXRG genotype (GG) had independent risk of the development of DR after adjusting for other co-founding factors (Table 3). Multiple SNPs on RXRG were detected because they are in linkage disequilibrium with each other.

Table 2. Result of comparisons of allelic and genotypic frequencies between the DR and NDR groups.

\begin{tabular}{|c|c|c|c|c|c|c|c|c|}
\hline \multirow[t]{3}{*}{ SNP } & \multirow[t]{3}{*}{ Allele } & \multicolumn{2}{|c|}{ Number } & \multicolumn{5}{|c|}{ Statistical test (P-value) } \\
\hline & & \multirow[t]{2}{*}{ DR } & \multirow[t]{2}{*}{ NDR } & \multirow[t]{2}{*}{ Allele } & \multicolumn{3}{|c|}{ Genotype } & \multirow[t]{2}{*}{ Hardy-Weinberg } \\
\hline & & & & & Case/control & Dominant & Recessive & \\
\hline rs 746332 & $\mathrm{~A} / \mathrm{C}$ & 80 & 128 & 0.0668 & 0.1769 & 0.3827 & 0.1238 & 0.9647 \\
\hline rs113471 & $\mathrm{C} / \mathrm{T}$ & 81 & 129 & 0.8582 & 0.7074 & 0.6471 & 0.9078 & 0.9790 \\
\hline rs2281986 & $\mathrm{C} / \mathrm{T}$ & 81 & 129 & 0.5500 & 0.5546 & 0.2873 & 0.3466 & 0.6271 \\
\hline rs283690 & $\mathrm{A} / \mathrm{G}$ & 81 & 129 & 0.6368 & 0.8945 & 0.8323 & 0.6712 & 1.0000 \\
\hline rs3818569 & $\mathrm{A} / \mathrm{G}$ & 81 & 129 & 0.0023 & 0.0057 & 0.0054 & 0.1668 & 0.3373 \\
\hline rs 3767356 & $\mathrm{~A} / \mathrm{G}$ & 80 & 128 & 0.3022 & 0.5111 & 0.9300 & 0.2674 & 0.9927 \\
\hline rs188230 & $\mathrm{C} / \mathrm{T}$ & 81 & 129 & 0.4653 & 0.7790 & 0.7613 & 0.5199 & 0.5974 \\
\hline rs1467664 & $\mathrm{C} / \mathrm{T}$ & 80 & 128 & 0.4511 & 0.7171 & 0.4815 & 0.4150 & 0.7397 \\
\hline rs 285429 & $\mathrm{C} / \mathrm{G}$ & 81 & 130 & 0.6679 & 0.8657 & 0.6121 & 0.6015 & 0.9509 \\
\hline
\end{tabular}

The $\mathrm{P}$ values were derived from the $\chi^{2}$ test. $\mathrm{DR}=$ diabetic retinopathy; $\mathrm{NDR}=$ non-proliferative diabetic retinopathy.

Table 3. Predictors of diabetic retinopathy by multivariate logistic regression analysis.

\begin{tabular}{|c|c|c|c|c|c|c|}
\hline \multirow[b]{2}{*}{ Factor } & \multicolumn{3}{|c|}{ Univariate } & \multicolumn{3}{|c|}{ Multivariate (adjusted) } \\
\hline & OR & $95 \% \mathrm{CI}$ & $\mathrm{P}$ & OR & $95 \% \mathrm{CI}$ & $\mathrm{P}$ \\
\hline Age & 0.988 & $0.958-1.019$ & 0.445 & 0.962 & $0.922-1.003$ & 0.071 \\
\hline Gender & 1.314 & $0.753-2.293$ & 0.336 & 1.033 & $0.51-2.094$ & 0.928 \\
\hline Diabetic duration & 1.008 & $1.004-1.011$ & 0.000 & 1.009 & $1.005-1.014$ & $<0.001$ \\
\hline BMI & 1.094 & $1.018-1.178$ & 0.018 & 1.052 & $0.97-1.14$ & 0.222 \\
\hline SBP & 1.025 & $1.009-1.042$ & 0.002 & 1.021 & $0.99-1.044$ & 0.061 \\
\hline DBP & 1.025 & $0.999-1.051$ & 0.062 & 1.011 & $0.976-1.048$ & 0.538 \\
\hline FPG & 1.006 & $1.001-1.010$ & 0.028 & 1.007 & $1.001-1.013$ & 0.025 \\
\hline Creatinine & 1.778 & $1.187-2.662$ & 0.005 & 1.478 & $0.934-2.337$ & 0.095 \\
\hline RXRG-GG & 2.745 & $1.460-5.159$ & 0.002 & 2.388 & $1.17-4.875$ & 0.017 \\
\hline
\end{tabular}

$\mathrm{BMI}=$ body mass index; $\mathrm{SBP}=$ systolic blood pressure; $\mathrm{DBP}=$ diastolic blood pressure; $\mathrm{FPG}=$ fasting plasma glucose; $\mathrm{RXRG}=$ retinoid-X receptor-gamma.

\section{DISCUSSION}

Not surprisingly, patients with DR had more cardiovascular risk factors than those without retinopathy. Our results were similar to the previous study, which reported that DR is an independent marker for the development of further cardiovascular disorders (Juutilainen et al., 2007). The pathological presentations of DR are characterized by increased vascular permeability, tissue ischemia and new vessel formation. Therefore, factors that influence these processes will have an important effect on the pathogenesis of DR. We identified that the SNP rs3818569 in the RXRG gene is closely correlated with the development of DR, either 
in allele or genotype frequency. The clinical importance of the detected SNP markers in the present study requires further functional evaluation to elucidate the exact role of genetic polymorphisms in the pathogenesis of DR.

RXR forms heterodimers in combination with peroxisome proliferator-activated receptors (PPAR) and aids in maintaining homeostasis in glucose and lipid metabolism (Shulman and Mangelsdorf, 2005). Thus, RXRG may play a role in the pathogenesis of type 2 diabetes. This was suggested in a previous study, in which an RXR agonist inhibited hepatic glucose production and increased peripheral glucose disposal (Davies et al., 2001). Our study included 1 SNP in the RXRG gene (rs3818569, but now merged into rs1128977) that had a positive correlation with the development of DR. Interestingly; this SNP was present at different frequencies among patients with or without diabetic nephropathy in our previous study (Hsieh et al., 2006). This indicates that this SNP may play an important role in the development of diabetic complications. Nevertheless, it is unknown whether retinopathy has similar genetic predisposing processes as nephropathy. A previous study attempted to answer this question but the study results are pending (Knowler et al., 2005).

This study had several limitations. The definition of retinopathy needs to be better clarified by different ophthalmologists. However, this bias may be minimized by dividing patients into 2 groups on the basis of disease severity. Second, the post-hoc analysis was performed using data from our previous study that was focused on diabetic nephropathy. Third, in our study, the patients with DR had diabetes for a longer average duration than those in the NDR group. Thus, our results must be interpreted with caution because duration of diabetes is the most important factor that influences the sequence of DR. In addition, duration of diabetes may modify the association between genetic variation, risk of DR, and severity, as suggested in a previous study (Reiner et al., 2003). Finally, this study had a case-control design and enrolled a relatively small number of patients. A larger, prospective study is needed that includes a functional assay to investigate the exact role of this SNP on the pathogenesis of chronic complications among patients with type 2 diabetes.

In conclusion, we identified the SNP rs3818569 in the RXRG gene, which was associated with the development of DR. Exploring the genetic factors that predispose patients to chronic complications of diabetes will allow identification of patients who are genetically predisposed to these complications and thus enable us to treat the underlying abnormalities earlier and more aggressively.

\section{ACKNOWLEDGMENTS}

Research supported by Grant from the National Science Council (\#NSC 98-2314-B016-004).

\section{REFERENCES}

Anonymous (1997). Clustering of long-term complications in families with diabetes in the diabetes control and complications trial. The Diabetes Control and Complications Trial Research Group. Diabetes 46: 1829-1839.

Anonymous (1998a). Intensive blood-glucose control with sulphonylureas or insulin compared with conventional treatment and risk of complications in patients with type 2 diabetes (UKPDS 33). UK Prospective Diabetes Study Group. Lancet 352: 837-853.

Anonymous (1998b). Tight blood pressure control and risk of macrovascular and microvascular complications in type 2 
diabetes: UKPDS 38. UK Prospective Diabetes Study Group. BMJ 317: 703-713.

Awata T, Inoue K, Kurihara S, Ohkubo T, et al. (2002). A common polymorphism in the 5'-untranslated region of the VEGF gene is associated with diabetic retinopathy in type 2 diabetes. Diabetes 51: 1635-1639.

Buraczynska M, Ksiazek P, Baranowicz-Gaszczyk I and Jozwiak L (2007). Association of the VEGF gene polymorphism with diabetic retinopathy in type 2 diabetes patients. Nephrol. Dial. Transplant. 22: 827-832.

Cahill GF Jr, Etzwiler LD and Freinkel N (1976). Editorial: "Control" and diabetes. N. Engl. J. Med. 294: 1004-1005.

Chai D, Wang B, Shen L, Pu J, et al. (2008). RXR agonists inhibit high-glucose-induced oxidative stress by repressing PKC activity in human endothelial cells. Free Radic. Biol. Med. 44: 1334-1347.

Chen Y, Huang H, Zhou J, Doumatey A, et al. (2007). Polymorphism of the endothelial nitric oxide synthase gene is associated with diabetic retinopathy in a cohort of West Africans. Mol. Vis. 13: 2142-2147.

Davies PJ, Berry SA, Shipley GL, Eckel RH, et al. (2001). Metabolic effects of rexinoids: tissue-specific regulation of lipoprotein lipase activity. Mol. Pharmacol. 59: 170-176.

Fong DS, Aiello L, Gardner TW, King GL, et al. (2003). Diabetic retinopathy. Diabetes Care 26: 226-229.

Fujisawa T, Ikegami H, Kawaguchi Y, Hamada Y, et al. (1998). Meta-analysis of association of insertion/deletion polymorphism of angiotensin I-converting enzyme gene with diabetic nephropathy and retinopathy. Diabetologia 41: 47-53.

Hsieh CH, Liang KH, Hung YJ, Huang LC, et al. (2006). Analysis of epistasis for diabetic nephropathy among type 2 diabetic patients. Hum. Mol. Genet. 15: 2701-2708.

Juutilainen A, Lehto S, Ronnemaa T, Pyorala K, et al. (2007). Retinopathy predicts cardiovascular mortality in type 2 diabetic men and women. Diabetes Care 30: 292-299.

Kastner P, Mark M and Chambon P (1995). Nonsteroid nuclear receptors: what are genetic studies telling us about their role in real life? Cell 83: 859-869.

Klein R, Klein BE, Moss SE, Davis MD, et al. (1984a). The Wisconsin epidemiologic study of diabetic retinopathy. II. Prevalence and risk of diabetic retinopathy when age at diagnosis is less than 30 years. Arch. Ophthalmol. 102: 520526.

Klein R, Klein BE, Moss SE, Davis MD, et al. (1984b). The Wisconsin epidemiologic study of diabetic retinopathy. III. Prevalence and risk of diabetic retinopathy when age at diagnosis is 30 or more years. Arch. Ophthalmol. 102: 527532.

Knowler WC, Coresh J, Elston RC, Freedman BI, et al. (2005). The family investigation of nephropathy and diabetes (FIND): design and methods. J. Diabetes Complications 19: 1-9.

Lesile RD and Pyke DA (1982). Diabetic retinopathy in identical twins. Diabetes 31: 19-21.

Mangelsdorf DJ and Evans RM (1995). The RXR heterodimers and orphan receptors. Cell 83: 841-850.

Parving HH, Tarnow L and Rossing P (1996). Genetics of diabetic nephropathy. J Am. Soc. Nephrol. 7: 2509-2517.

Ray D, Mishra M, Ralph S, Read I, et al. (2004). Association of the VEGF gene with proliferative diabetic retinopathy but not proteinuria in diabetes. Diabetes 53: 861-864.

Reiner AP, Agardh E, Teramura G, Gaur P, et al. (2003). Diabetes duration may modify the association between genetic variation in the glycoprotein Ia subunit of the platelet collagen receptor and risk of severe diabetic retinopathy: a working hypothesis. Thromb. Haemost. 89: 142-148.

Roy MS, Hallman DM, Fu YP, Machado M, et al. (2009). Assessment of 193 candidate genes for retinopathy in African Americans with type 1 diabetes. Arch. Ophthalmol. 127: 605-612.

Shulman AI and Mangelsdorf DJ (2005). Retinoid x receptor heterodimers in the metabolic syndrome. N. Engl. J. Med. 353: 604-615.

Suganthalakshmi B, Anand R, Kim R, Mahalakshmi R, et al. (2006). Association of VEGF and eNOS gene polymorphisms in type 2 diabetic retinopathy. Mol. Vis. 12: 336-341. 